\title{
Dementia Knowledge among Kuwait University Students: a Descriptive Study
}

\author{
Fahad Manee*, Ghadeer AlHaddad, Sarah AlAli, and Mehdi Rassafiani \\ Department of Occupational Therapy, Kuwait University, Kuwait
}

*Corresponding author: Fahad Safah Kayed Manee, Department of Occupational

Therapy, Faculty of Allied Health Sciences, Kuwait University, Kuwait.

Received Date: October 30, 2019

Published Date: November 06, 2019

\section{Abstract}

Background: In regard to prevention and early intervention for dementia, knowledge of the population is a key factor. The aim of this study is to determine the level of understanding about dementia among students at all campuses at Kuwait University and so be able to better plan for future intervention.

Methods: A cross-sectional study was conducted in order to examine the knowledge of dementia among Kuwait University students across different campuses. An Arabic version of the DKAS was cross culturally developed and used in this study. The comparison of the DKAS subscales and the dementia total score were obtained.

Results: A total of 1350 students participated in this study. The results indicated that the students in different campuses had a significant difference in the dementia total score $(\mathrm{p}=0.000)$ as well as a significant difference between all subscales of the DKAS. Total score of dementia knowledge among students in all campuses was a mean of 15.09 out of 25 and S.D of 3.05. The Causes and Characteristics subscale was ( $p=0.000$ ) with a mean of 4.22 out of 7. The Communication and Behavior subscale was $(p=0.005)$ with a mean of 2.88 out of 6 . The Care Consideration subscale was $(p=0.019)$ with a mean of 4.67 out of 6 . The Risks and Health Promotion subscale was $(p=0.000)$ with a mean of 3.31 out of 6 .

Conclusion: The baseline knowledge of the students was moderate. Although there were differences in students' knowledge across all campuses, all students required improved knowledge of dementia. This will help us to implement more appropriate care and support.

Keywords: Dementia; Early intervention; Health promotion

Abbreviations: WHO: World Health Organization; IRB: Institutional Review Board; DKAS: Dementia Knowledge Assessment Scale; SPSS: Statistics Package for the Social Sciences

\section{Background}

Dementia is a disease of cognitive decline that interferes with the person's daily functions and behavior. However, it is not a normal part of aging. Dementia is one of the World health organization's (WHO) public priorities as approximately 50 million people worldwide are currently living with dementia. According to WHO's results, dementia is the seventh highest cause of death [1]. Worldwide, every three seconds, there is a new case of dementia, and the number is expected to triple to 152 million by 2050 [2]. Dementia is an umbrella term that can be categorized into various diseases. The most common cause of dementia, $60 \%$ to $80 \%$ of all cases is Alzheimer's disease [3].
Globally, undetected dementia is high among various countries. Approximately $60 \%$ of people with dementia are not detected in the community [4]. Education of various symptoms of dementia is needed for early detection and future health. Health care professionals should take lead roles for the improvement of dementia care settings. Improved quality of care in general hospitals should be considered as a priority in the Department of Health and aging services. Health care students' knowledge was assessed to help determine the quality of services provided for dementia patients in the clinical field. Non-health care related students' knowledge was determined to emphasize the efficacy 
of care that was provided for dementia patients [5,6]. A review of research specifically focusing on college and university students among various countries was conducted to address the gaps of knowledge about dementia among the students. Most studies in the review related to the knowledge of students in America and Europe with a few additional studies covering parts of Asia [7].

According to the global impact of dementia, about 22.9 million people in Asia live with dementia [2]. Based on a systematic review of 33 studies in Eastern Mediterranean countries, the prevalence of dementia was found to be high [8]. However, only a limited number of studies investigated the level of knowledge about dementia among university students in Asian countries. A study in Malaysia analyzed the level of knowledge and attitude toward older adults among health care students. The results showed that the majority of students had moderate knowledge of the topic and held a positive attitude toward aging. A significant correlation between knowledge of aging and attitudes toward older adults was identified [9].

Another study in Korea determined the level of knowledge about dementia of both health and non-health-related students. The results of this study demonstrated that health-related students had greater knowledge and more positive attitudes toward dementia compared to non-health-related students. The dementia knowledge scores of health-related students were significantly higher than those of non-health-related students [5]. Only one study in the Middle East, which focused on the attitude of medical students toward old people in Ajman, United Arab Emirates was found. The results showed that the first-year students had limited knowledge of and care for the elderly, compared to final-year and internship students who both had some theoretical and clinical experience in geriatrics [10]. This limited study does not provide an appropriate picture about dementia among particular population. Since Middle East countries include diversity of cultures and economics, other studies are critical to understand the knowledge of dementia. Therefore, the aim of this study was to analyze the level of knowledge about dementia among Kuwait University students in all faculties.

\section{Methods}

\section{Participants}

The participants of this study were undergraduate students from various academic years at Kuwait University. They were enrolled at Kuwait University during the academic year of 20172018. The students were from different campuses including Jabriya, a health-related campus, Shuwaikh, a non-health related campus, Kaifan a non-health related campus, Adailiya a health and nonhealth related campus and Khalidiya a non-health related campus. Jabriya campus included the colleges of Medicine, Dentistry, Pharmacy and Allied Health Sciences. Shuwaikh campus included the colleges of Business Administration, Sociology, and Law. Kaifan campus included the colleges of Arts, Education, and Sharia and Islamic studies. Adailya campus included college of Computing Sciences and Engineering and college of Life Sciences. Khalidya campus included college of Petroleum and Engineering and college of Sciences.

In each campus, students were randomly selected from the cafeterias, campus halls, and waiting areas. Two research assistants participated in collecting data across all campuses. The students selected for this study were given a brief overview of the study. They were also informed about the purpose and the significance of the study. The students were assured that participation was anonymous and voluntary. Each participant was required to sign an informed consent prior to participating in the study. The study was reviewed and approved by the Institutional Review Board (IRB) for Research involving human participants.

\section{Outcome measures}

The students' demographic information and knowledge about dementia were collected using two questionnaires. They filledout the demographic questionnaire as well as the Arabic version of the Dementia Knowledge Assessment Scale (DKAS). The first questionnaire, which pertained to the student's demographic information included gender, age, faculty and academic year. The following questions were included in the questionnaire: if there was someone in the family diagnosed with dementia, if they attended any presentations, workshops, or conferences about dementia, if they would like to attend and listen to a presentation, seminar or conference about dementia or Alzheimer's disease, and if they would like to receive special training about the management of people with dementia or Alzheimer's disease. The second assessment used was the Dementia Knowledge Assessment scale (DKAS). The DKAS is a knowledge questionnaire that was created in the Wicking Dementia Research and Education Centre, Australia, the University of Tasmania in 2017. This questionnaire was established to determine the level of knowledge of dementia among community members including students, and health care professionals and to promote effective educational intervention as well as provide care and support. This questionnaire contains 25 items and 4 subscales.

The first subscale is causes and characteristics, which focuses on the biological and pathological aspect of dementia. The second subscale is communication and behavior, which contains the psychological features of the disease and how a person with dementia interacts in the world. The third subscale is care considerations, which focuses on the symptoms that are applicable to the arrangement and formation of care. The last subscale is risks and health promotion, which focuses on risk factors and conditions that are associated with or mistaken for dementia [11]. The DKAS questionnaire was a modified likert scale, and included five response options, false, probably false, probably true, true and I don't know. It was modified in to three options true, false or I don't know in order to simplify the questionnaire for the students. The English language version of the DKAS was valid and reliable. It has a high internal consistency with scale (0.7-0.90) without evidence of potential redundancy that can occur with very high coefficients. This shows that it is a reliable instrument to measure the level 
of dementia knowledge with suitable inter item correlation. In addition to that, it has good construct validity since it measures significant increase of dementia knowledge as well as having good discriminative capabilities, enabling comparison of the results of different groups [12].

In this study a cross cultural adaptation and translation of the Arabic-language version of the DKAS was developed. A crosscultural adaptation is defined as a "process which looks at both language (translation) and cultural adaptation issues in the process of preparing a questionnaire for use in another setting [13]. Research assistance in this study utilized the Arabic version of the DKAS since the majority of Kuwait University students use Arabic as their first language. A pilot study was performed to check the applicability and accuracy of the Arabic version of the DKAS [13].

\section{Data analysis}

All analyses were established using SPSS software version 24 . Descriptive statistics including percentage, mean and standard deviation were applied. We used one-way ANOVA to determine the results between the four subscales, causes and characteristics, communication and behavior, care consideration, and risk and health promotion as well as determining the dementia knowledge total score. In addition to that, Post Hoc tests were also used to determine the level of knowledge among students in all colleges and in all campuses at Kuwait University.

\section{Results}

\section{Data characteristics and demographic information}

In total, 1350 respondents with a response rate of $93.1 \%$ volunteered to complete the social demographic questionnaire and the DKAS questionnaire. $22.9 \%$ of the students were male and $77.1 \%$ female. $61 \%$ of the of the students' ages were between $18-21$ years old and they were from different years of studying at Kuwait University. Students participated from various campuses and colleges. The college of Allied Health Science, which is located on the Jabriya campus, had the highest number of participants with the college of Computing Sciences and Engineering in Adailiya campus having the lowest (Table 1). A range of results were gathered based on the following questions, do you have someone in the family diagnosed with dementia, have you attended any presentations, workshops or conferences about dementia and weather you want to receive special training about dementia. Results showed that $80 \%$ of the students did not know anyone diagnosed with dementia and $20 \%$ knew someone diagnosed with dementia. $91 \%$ of the participants did not attend a presentation, a conference, or a workshop about dementia. $60 \%$ of the students expressed their interests to receive special training about dementia (Table 1).

Table 1: Students in all campuses and colleges.

\begin{tabular}{|c|c|c|c|c|}
\hline Campus & $\begin{array}{l}\text { Percentage of Students in All } \\
\text { Campuses }\end{array}$ & Colleges & Number of Participants & Percentage \\
\hline \multirow{4}{*}{ Jabriya Campus } & \multirow{4}{*}{$33.90 \%$} & Medicine & 103 & 7.6 \\
\hline & & Dentistry & 38 & 2.8 \\
\hline & & Pharmacy & 48 & 3.6 \\
\hline & & Allied Health Sciences & 269 & 19.9 \\
\hline \multirow{3}{*}{$\begin{array}{l}\text { Shuwaikh } \\
\text { Campus }\end{array}$} & \multirow{3}{*}{$22.20 \%$} & Business & 136 & 10.1 \\
\hline & & Law & 40 & 3 \\
\hline & & Sociology & 124 & 9.2 \\
\hline \multirow{3}{*}{ Kaifan Campus } & \multirow{3}{*}{$21.00 \%$} & Arts & 121 & 9 \\
\hline & & Education & 110 & 8.1 \\
\hline & & Shariaa and Islamic studies & 51 & 3.8 \\
\hline \multirow{2}{*}{ Adailya Campus } & \multirow{2}{*}{$6.70 \%$} & Life Sciences & 74 & 5.5 \\
\hline & & Computing Sciences and Engineering & 16 & 1.2 \\
\hline \multirow{2}{*}{$\begin{array}{l}\text { Khalidiya } \\
\text { Campus }\end{array}$} & \multirow{2}{*}{$16.20 \%$} & Petroleum and Engineering & 125 & 9.3 \\
\hline & & Sciences & 94 & 7 \\
\hline
\end{tabular}

\section{Comparison between groups}

ANOVA was used to compare dementia knowledge among students studying in various campuses. The results showed that there was a significant difference in the dementia total score ( $p=$ .000 ) and all subscales of the DKAS (Table 2). A Post hoc analysis was performed to understand the differences between all campuses. The results showed that students in Jabriya and Adailiya Campus had higher level of knowledge compared to the other campuses (Table 3). Table 4 showed that students in health and non-health related courses had low scores in the causes and characteristics subscale, the communication and behavior subscale and the risk and health promotion subscale. In contrast, in the care consideration subscale, all health and non-health related students had fair scores. The results showed that there was a significant difference between the knowledge of Jabriya campus and other campuses except Adailiya campus (Table 2-4).

A t-test analysis was employed to differentiate between the various groups. Initially, the knowledge of students who know someone in the family diagnosed with dementia was compared with that of students who did not. Then, the knowledge of students 
who attended any presentations, conferences, or workshops about dementia was compared with those who had not. Finally, the knowledge of students who wanted to receive special training

Table 2: Results of ANOVA for dementia total score and dementia.

\begin{tabular}{|c|c|c|c|c|c|}
\hline \multicolumn{2}{|c|}{ Dementia Knowledge Total Score } & Mean & S.D & $\mathbf{F}$ & Sig. \\
\hline \multirow{4}{*}{ Dementia Knowledge Sub Scales } & Causes and Characteristics & 4.22 & 1.38 & 19.2 & 0 \\
\hline & Communication and Behavior & 2.88 & 1.2 & 3.72 & 0.005 \\
\hline & Care and Consideration & 4.67 & 1.3 & 2.97 & 0.019 \\
\hline & Risk and Health Promotion & 3.31 & 1.26 & 12.86 & 0 \\
\hline
\end{tabular}

Table 3: Dementia Total Score in all campuses.

\begin{tabular}{|c|c|c|c|}
\hline Campuses in Kuwait University & $\begin{array}{c}\text { Mean of Dementia Total } \\
\text { Score } \mathbf{2 5}\end{array}$ & S.D of Dementia Total Score & $\begin{array}{c}\text { Comparison of Jabriya campus with } \\
\text { other campuses }\end{array}$ \\
\hline Shuwaikh Campus & 14.65 & 2.747 & 0 \\
\hline Khaldiya Campus & 14.79 & 2.932 & 0 \\
\hline Jabriya Campus & 15.87 & 3.326 & $-\cdots$ \\
\hline Adailiya Campus & 16.02 & 2.82 & 0.993 \\
\hline Kaifan Campus & 14.2 & 2.633 & 0 \\
\hline
\end{tabular}

Table 4: DKAS subscales in all campuses.

\begin{tabular}{|c|c|c|c|c|}
\hline Subscales & Campus & Mean & S.D & Comparison of Jabriya Campus with other campuses \\
\hline \multirow{5}{*}{ Causes and Characteristics } & Shuwaikh & $3.91 / 7$ & 1.23 & 0 \\
\hline & Khalidiya & $4.24 / 7$ & 1.35 & 0.009 \\
\hline & Jabriya & $4.60 / 7$ & 1.45 & - \\
\hline & Adailiya & $4.47 / 6$ & 1.31 & 0.884 \\
\hline & Kaifan & $3.86 / 6$ & 1.28 & 0 \\
\hline \multirow{5}{*}{ Communication and Behavior } & Shuwaikh & $2.91 / 6$ & 1.14 & 0.987 \\
\hline & Khalidiya & $2.63 / 6$ & 1.14 & 0.006 \\
\hline & Jabriya & $2.96 / 6$ & 1.3 & - \\
\hline & Adailiya & $3.07 / 6$ & 1.22 & 0.939 \\
\hline & Kaifan & $2.83 / 6$ & 1.11 & 0.647 \\
\hline \multirow{5}{*}{ Care Consideration } & Shuwaikh & $4.69 / 6$ & 1.23 & 1 \\
\hline & Khalidiya & $4.70 / 6$ & 1.32 & 1 \\
\hline & Jabriya & $4.70 / 6$ & 1.34 & - \\
\hline & Adailiya & $4.98 / 6$ & 1.17 & 0.306 \\
\hline & Kaifan & $4.48 / 6$ & 1.32 & 0.166 \\
\hline \multirow{5}{*}{ Risk and Health Promotion } & Shuwaikh & $3.13 / 6$ & 1.26 & 0 \\
\hline & Khalidiya & $3.23 / 6$ & 1.27 & 0.001 \\
\hline & Jabriya & $3.61 / 6$ & 1.28 & - \\
\hline & Adailiya & $3.51 / 6$ & 1.19 & 0.903 \\
\hline & Kaifan & $3.03 / 6$ & 1.11 & 0 \\
\hline
\end{tabular}

The results showed that the students who knew someone in the family diagnosed with dementia had higher knowledge than students who did not know someone in the family diagnosed with dementia. In addition, there was a significant difference among the care consideration subscale, which emphasized that the students about management of people with dementia was compared with students who do not want to receive special training on this topic. 
students who had not attend any presentations, conferences, or workshops. The results also showed that there was a significant difference between all subscales between the students who wanted to receive a special training about the management of people with dementia and those students who did not (Table 5 \& 6).

Table 5: The knowledge of students who know and did not know a family member with dementia.

\begin{tabular}{|c|c|c|c|c|c|c|c|c|}
\hline & & & mean & Std. Deviation & $\mathbf{F}$ & Sig. & $\mathbf{t}$ & P. value \\
\hline \multirow{2}{*}{ Causes and Characteristics } & yes & 267 & $4.44 / 7$ & 1.36 & \multirow{2}{*}{0} & \multirow{2}{*}{0.985} & \multirow{2}{*}{2.872} & \multirow{2}{*}{0.004} \\
\hline & no & 1069 & $4.17 / 7$ & 1.383 & & & & \\
\hline \multirow{2}{*}{ Communication and Behavior } & yes & 269 & $2.91 / 6$ & 1.252 & \multirow{2}{*}{0.453} & \multirow{2}{*}{0.501} & \multirow{2}{*}{0.426} & \multirow{2}{*}{0.67} \\
\hline & no & 1073 & $2.88 / 6$ & 1.182 & & & & \\
\hline \multirow{2}{*}{ Care Consideration } & yes & 270 & $4.87 / 6$ & 1.224 & \multirow{2}{*}{7.443} & \multirow{2}{*}{0.006} & \multirow{2}{*}{2.725} & \multirow{2}{*}{0.007} \\
\hline & no & 1073 & $4.63 / 6$ & 1.319 & & & & \\
\hline \multirow{2}{*}{ Risks and Health Promotion } & yes & 269 & $3.35 / 6$ & 1.301 & \multirow{2}{*}{0.544} & \multirow{2}{*}{0.461} & \multirow{2}{*}{0.594} & \multirow{2}{*}{0.552} \\
\hline & no & 1069 & $3.3 / 6$ & 1.247 & & & & \\
\hline \multirow{2}{*}{ Dementia knowledge total score } & yes & 265 & $15.75 / 25$ & 3.164 & \multirow{2}{*}{0.009} & \multirow{2}{*}{0.926} & \multirow{2}{*}{2.822} & \multirow{2}{*}{0.005} \\
\hline & no & 1060 & $14.98 / 25$ & 3.012 & & & & \\
\hline
\end{tabular}

Table 6: The knowledge of students who want and did not want to receive special training.

\begin{tabular}{|c|c|c|c|c|c|c|c|c|}
\hline & & & Mean & Std. Deviation & $\mathbf{f}$ & Sig. & $\mathbf{t}$ & P. value \\
\hline \multirow{2}{*}{ Causes and characteristics } & yes & 778 & 4.34 & 1.385 & \multirow{2}{*}{1.427} & \multirow{2}{*}{0.232} & \multirow{2}{*}{3.318} & \multirow{2}{*}{0.001} \\
\hline & no & 547 & 4.08 & 1.367 & & & & \\
\hline \multirow{2}{*}{ Communication and behavior } & yes & 782 & 2.96 & 1.204 & \multirow{2}{*}{0.053} & \multirow{2}{*}{0.817} & \multirow{2}{*}{2.835} & \multirow{2}{*}{0.005} \\
\hline & no & 549 & 2.77 & 1.173 & & & & \\
\hline \multirow{2}{*}{ Care consideration } & yes & 783 & 4.83 & 1.24 & \multirow{2}{*}{7.395} & \multirow{2}{*}{0.007} & \multirow{2}{*}{5.178} & \multirow{2}{*}{0} \\
\hline & no & 549 & 4.46 & 1.358 & & & & \\
\hline \multirow{2}{*}{ Risks and health promotion } & yes & 779 & 3.41 & 1.238 & \multirow{2}{*}{0.027} & \multirow{2}{*}{0.869} & \multirow{2}{*}{3.273} & \multirow{2}{*}{0.001} \\
\hline & no & 549 & 3.18 & 1.273 & & & & \\
\hline \multirow{2}{*}{ Dementia knowledge total score } & yes & 773 & 15.53 & 3.056 & \multirow{2}{*}{0.736} & \multirow{2}{*}{0.391} & \multirow{2}{*}{6.01} & \multirow{2}{*}{0} \\
\hline & no & 542 & 14.51 & 2.93 & & & & \\
\hline
\end{tabular}

\section{Discussion}

Dementia is an incurable disease that increases among the elderly year after year. The use of DKAS helped the research team to have a base line about the level of knowledge about dementia among Kuwait University students. The results of this study showed a low level of knowledge among students in all campuses. This is in agreement with the literature which found that two hundred and forty-two final year undergraduates from health and social care professionals in Hong Kong had poor knowledge of dementia [14].

Due to this low level of knowledge about dementia, early diagnoses may not be applied as it should be and dementia management might be delayed. Also new strategies and techniques for treating people with dementia may not be implemented. Students are the future target. Some of them may either work with people with dementia or may know someone with dementia, in particular those students who are in the health-related fields. In the future, they will also provide care and support to a caregiver or a family member who has dementia.

This study shows that student from health care departments (Jabriya and Adailiya) had a moderate knowledge of $63.48 \%$ and $64.08 \%$, respectively. In the literature, health care students in various countries had a moderate knowledge about dementia with a percentage of (68.9\%), which emphasizes that our results are similar to the literature. Although dementia knowledge is part of their education, better results were expected from the health care field students. In the future, they are expected to provide possible assessments of and treatments for people with dementia [11].

Based on the results of the four subscales in the DKAS, students who are related to the health care fields in the Jabriya and Adailiya campuses had higher knowledge in the first subscale (causes and characteristic) and the fourth subscale (risk and health promotion). Health related students were more educated about the pathological aspects of the brain and the risk factors of dementia. However, the results were expected to be higher than this. For the second subscale (communication and behavior), students in the Adailiya and Jabriya campuses had higher results than the other campuses. Students in these two campuses had a higher knowledge of how to interact, communicate and behave with a person with dementia.

On the other hand, students from Khaldiya campus had low results in the (communication and behavior) subscale. On this campus, the education background of students from the College of Petroleum and Engineering and the College of Science their education is related to mathematics and equations, which mean that there may be less emphasis on communication between people 
[15]. For the third subscale (care consideration), all the students, whether from health or non -health related fields showed high results in this subscale. Such results show that caring for the elderly is necessary according to the Islamic religion and Middle Eastern culture.

The elderly in Kuwait and the Middle East as whole mostly live with their families rather than nursing homes. According to the Islamic religion and the Middle Eastern culture, it is important for the elderly to live with their families. They can spend time with their children and spouses, which in turn improves their quality of life and wellbeing as composed to living in nursing homes [16]. The majority of the students who knew someone in the family diagnosed with dementia had a higher sore in the (care consideration subscale) than the other subscales and scored the least in the (communication and behavior subscale). This indicates that communication and behavior should be taken as an important consideration since communication is an essential component in establishing a relationship with people with dementia and helps to fulfill their social needs [17]. The majority of the studies in the literature focused on students' attitude and knowledge toward people with dementia but did not specifically consider their knowledge about the communication and behavior of people with dementia [18]. The knowledge of the students who attended presentations, conferences or workshops about dementia is similar to the knowledge of students who did not. For students who wanted to receive special training, it appears that they were interested in dementia and thought that was important to receive specialized training since dementia is a life -threatening disease.

One of the limitations of this study was that the Nursing College was not included in this study. In Kuwait, the Nursing College is under the remit of the Public Authority for Applied Education and Training and not under Kuwait University. Therefore, researchers were not able to analyze the nursing students' level of knowledge about dementia and compare it with the other health field related students. It is important to examine nursing students' level of knowledge about dementia since they also provide care at the hospitals and at patients' homes [19]. Further recommendations such as dementia awareness in public places should increase the level knowledge of students in Kuwait University, and conferences or workshops should be offered on various campuses to increase awareness and provide health promotion.

\section{Conclusion}

The baseline knowledge of the students was moderate. Although there were differences in the results, we should increase awareness among all campuses at Kuwait University especially on Adailiya campus, which includes Faculty of Life Sciences and Jabriya campus, which includes Faculty of Medicine, Faculty of Dentistry, Faculty of Pharmacy and Faculty of Allied Health Sciences. Students at the faculties on these campuses require training since they will be working in the medical field. This will help in promoting more appropriate care and effective intervention for dementia patients. There is a pressing need in Kuwait to improve undergraduate education on dementia in order to help future doctors obtain the ability to provide competent care for patients. It is suggested to refine existing curricula covering dementia and to build an evidence-base for successful dementia-specific teaching interventions in Kuwait.

\section{Declarations}

\section{Ethical approval and consent to participate}

Ethical approval for the collection of volunteer participants' dementia knowledge and demographic information was granted by Kuwait University, International Review Board for research involving human participants. (Ref no.1046). The consent that we obtained from the participants was written and they were informed in the consent that all information will remain confidential. Neither name or nor address will be recorded in the assessment. There is no obligation or compulsion for the participants to participate in the study and they have the freedom to agree or disagree to participate. The participants may withdraw from the research any time. This research will not have any effect on the academic standing of the participants.

\section{Consent for publication}

Not applicable

\section{Availability of data and materials}

The datasets of the study are publicly available at the Health Science Center, Faculty of Allied Health Sciences, Occupational Therapy Department, Kuwait University and can be obtained after submitting a data use agreement to the research team, however the confidential participant's data will not be shared.

\section{Competing Interests}

The authors declare that they have no competing interests.

\section{Funding}

This research was not supported by Kuwait University.

\section{Author's Contribution}

FM contributed to the drafting and critical review of the manuscript as well as providing helpful comments on theoretical conceptualization. GH and SA collected all data and prepared the manuscript. MR critically revised the manuscript and conducted data analysis.

\section{Acknowledgements}

The authors wish to thank the Deans and Assistant Deans of all colleges at all campuses for giving us the approval to distribute the questionnaire among the students at Kuwait University.

\section{References}

1. Prince M, Guerchet M, Prina M (2015) The epidemiology and impact of dementia: current state and future trends. Geneva: World Health Organization

2. Prince M, Wimo A, Guerchet M, Ali GC, Wu YT, et al. (2015) World Alzheimer Report 2015-The Global Impact of Dementia. An analysis of prevalence, incidence, cost and trends. Dementia Alzheimer's Disease International (ADI). 
3. Alzheimer's Association (2016) Alzheimer's disease facts and figures. Alzheimer's \& Dementia 12(4): 459-509.

4. Lang L, Clifford A, Wei L, Zhang D, Leung D, et al. (2017) Prevalence and determinants of undetected dementia in the community: a systematic literature review and a meta-analysis. BMJ open 7(2): e011146.

5. Yong MH, Yoo CU, Yang YA (2015) Comparison of knowledge of and attitudes toward dementia between health-related and non-healthrelated university students. Journal of physical therapy science $27(12)$ : 3641-3643.

6. Jacinto AF, Citero VD, Lima Neto JL, Boas PJ, Valle AP, et al. (2017) Knowledge and attitudes towards dementia among final-year medical students in Brazil. Rev Assoc Med Bras 63(4): 366-370.

7. Basri A, Farhan MA, Subramaniam P, Ghazali SE, Singh DK (2017) A Review of Knowledge and Attitudes Towards Dementia Among College and University Students. Journal of Clinical \& Diagnostic Research 11(11).

8. Yaghmour SM, Bartlett R, Brannelly T (2018) Dementia in Eastern Mediterranean countries: A systematic review. Dementia 18(7-8): 26352661.

9. Singh DKA, Subramaniam P, Rahman NNAA, Rusly FZ, Ghazali SE (2018) Knowledge and Attitude towards Ageing among Health Science University Students. Journal of the Liaquat University of Medical and Health Sciences 17(1): 36-41.

10. Sheikh RB, Mathew E, Rafique AM, Suraweera RS, Khan H, et al. (2013) Attitude of medical students toward old people in Ajman, United Arab Emirates. Asian Journal of Gerontology and Geriatrics 8: 85-89.

11. Annear MJ, Toye C, Elliott KE, McInerney F, Eccleston C, et al. (2017) Dementia knowledge assessment scale (DKAS): confirmatory factor analysis and comparative subscale scores among an international cohort. BMC geriatrics 17(1): 168.
12. Annear MJ, Eccleston CE, McInerney FJ, Elliott KE, Toye CM, et al. (2016) A new standard in dementia knowledge measurement: Comparative validation of the dementia knowledge assessment scale and the alzheimer's disease knowledge scale. Journal of the American Geriatrics Society 64(6): 1329-1334.

13. Beaton DE, Bombardier C, Guillemin F, Ferraz MB (2000) Guidelines for the process of cross-cultural adaptation of self-report measures. Spine 25(24): 3186-3191.

14. T Kwok, KC Lam, A Yip, F Ho (2011) Knowledge of Dementia Among Undergraduates in the Health and Social Care Professions in Hong Kong. Social Work in Mental Health 9(4): 287-301.

15. Ghosh P, Mittal RK (2017) Challenges in strengthening the Communication and Behavioral skills for greater employability of engineering students: A study of NCR Delhi (India). International Journal of Management Excellence 8(3): 1013-1022.

16. Abdelmoneium AO, Alharahsheh ST (2016) Family home caregivers for old persons in the Arab region: perceived challenges and policy implications. Open Journal of Social Sciences 4(01):151.

17. Machiels M, Metzelthin SF, Hamers JP,Zwakhalen SM (2017) Interventions to improve communication between people with dementia and nursing staff during daily nursing care: a systematic review. International journal of nursing studies 66: 37-46.

18. Alushi L, Hammond JA, Wood JH (2015) Evaluation of dementia education programs for pre-registration healthcare students-a review of the literature. Nurse Education Today. Sep 1;35(9):992-998.

19. Eccleston CE, Lea EJ, McInerney F, Crisp E, Marlow A, et al. (2015) An investigation of nursing students' knowledge of dementia: A questionnaire study. Nurse education today 35(6): 800-805. 